Association for Information Systems

AIS Electronic Library (AISeL)

WHICEB 2014 Proceedings

Wuhan International Conference on e-Business

Summer 6-1-2014

\title{
Research on the Granted Patent Distribution of the Energy-saving and Environmental Protection Industry in China
}

Yongzhong Qiao

Intellectual Property Research Institute, Xiamen University, China

Qi Liang

Intellectual Property Research Institute, Xiamen University, China, 21068039@qq.com

Follow this and additional works at: http://aisel.aisnet.org/whiceb2014

\section{Recommended Citation}

Qiao, Yongzhong and Liang, Qi, "Research on the Granted Patent Distribution of the Energy-saving and Environmental Protection Industry in China" (2014). WHICEB 2014 Proceedings. 18.

http://aisel.aisnet.org/whiceb2014/18 


\title{
Research on the Granted Patent Distribution of the Energy-saving and Environmental Protection Industry in China
}

\author{
Yongzhong Qiao ${ }^{1}$, Qi Liang ${ }^{2 *}$ \\ ${ }^{1}$ Intellectual Property Research Institute, Xiamen University, China \\ ${ }^{2}$ Intellectual Property Research Institute, Xiamen University, China
}

\begin{abstract}
By analyzing the granted patents distribution of the energy-saving and environmental protection industry in China from 2008 to 2013, the conclusion can be reached: firstly, technological innovations of the energy-saving industry are focused on the environmentally air-conditioning and heat pump technical field, and technological innovations of the resources recycling industry is mainly concentrated on the food waste treatment and comprehensive utilization technical field and the urban sewage sludge recycling technical field, and technological innovations of the environmental management industry is highly focused on the high concentration organic wastewater control technical field; secondly, the granted patents distributions of the key strategic technical fields are unbalanced, of which the granted patents of the environmental management industry have the largest share; thirdly, the domestic granted patents distributions are basically similar to that of foreign granted patents in the energy-saving and environmental protection industry in China, but the domestic granted patents numbers are more than the foreign granted patents numbers.
\end{abstract}

Key words: energy-saving, environmental protection, granted patent, distribution

\section{INTRODUCTION}

With the severity of the global environmental issues and the shortage of energy resources, it is important to research on the granted patents distributions of the energy-saving and environmental protection technical fields for the development of related industry. The energy-saving and environmental protection industry is one of seven strategic emerging industries in $\mathrm{China}^{[1]}$ and it is also one of major industry domains of the Twelfth Five-Year Development Plan in China. The development of the energy-saving and environmental protection industry is of great importance to ease the pressure on traditional energy consumption, foster the new economic growth point and develop the emerging industries.

The development of the energy-saving and environmental protection industry is inseparable from technological innovation. Patent is one of the most reliable measures of the most direct indicators of technological innovation ${ }^{[2]}$, which would reflect the latest trends of researches in the industry and make companies develop their own technological strategies ${ }^{[3]}$. The patent system may improve the green technological innovation capability through a continuous cycle process: technological exploitation - protection - utilization improvement - protection - utilization. ${ }^{[4]}$ In 2012, the patent applications of the low-carbon technology and the energy-saving technology having been advanced examined by State Intellectual Property Office in China (SIPO). ${ }^{[5]}$ This system is conducive to promote the industrial management of the energy-saving technology, which will further promote innovations in the energy-saving and environmental protection industry. ${ }^{[6]}$

Researches on the energy-saving and environmental protection industry have attracted more and more scholars' attentions in home and abroad, because China ranked it as one of strategic emerging industries in 2010. Lots of works have done in the existing researches on the relative field of the industry, such as trends and development, strategies and measures, experience and creation, etc. Though plenty of results of the study have

\footnotetext{
*Corresponding author. Email: 21068039@qq.com (Qi Liang)
} 
been carried on, most researches are based on the qualitative analysis from the macro perspective, lacking of quantitative and empirical research on patent issues of the energy-saving and environmental protection industry. The quantitative and empirical analysis of patents is in favor of clearing the difference in innovation ability and the technological gap of between domestic and foreign technical fields. ${ }^{[7]}$ In that way, we would figure out more effective strategies to further develop the industry of China.

A developing trend of patents is one of an important indicator of industrial development, and the use of patent indicators to quantitative analysis the level of industrial technology and the innovation capability is a new research trend. ${ }^{[8]}$ It is the most common method to analyze the steady exponential growth characteristics of the patent document of related industrial technologies which can determine technological innovation activities in the industry. ${ }^{[7][9]}$ In order to clarify the technological development characteristics of the energy-saving and environmental protection industry and promote the industry development in China, we analyzed quantitatively the industry development status and trends of the energy-saving and environmental protection industry by the method of patent-bibliometric.

\section{DATA SOURCE AND INDUSTRY CLASSIFICATION}

In this article, the granted patents statistics is searched by IPC (International Patent Classification) in the platform of patent-searching system of Patent Star (website: http://searchtel. patentstar.com.cn/) from 2008 to 2013; and the information of the granted patents of the energy-saving and environmental protection industry is analyzed; then the development trends and patent problems in the industry in China are exposed.

The energy-saving and environmental protection industry is divided into the energy-saving industry, the resources recycling industry and the environmental management industry. Their main technical areas involved the International Patent Classification (IPC) symbols are based on the "Patent Search Handbook in Strategic Emerging Industries". [10]

\section{THE GRANTED PATENTS DISTRIBUTION OF THE ENERGY-SAVING AND ENVIRONMENTAL PROTECTION INDUSTRY}

\subsection{The overall features of the granted patents}

\subsubsection{The distribution of granted patents in three sub-industries}

Based on the statistics of granted patents in nearly six years of the energy-saving and environmental protection industry in China, we can draw some features of the development status and trends of patented technology in energy-saving, resources recycling and environmental management industries.

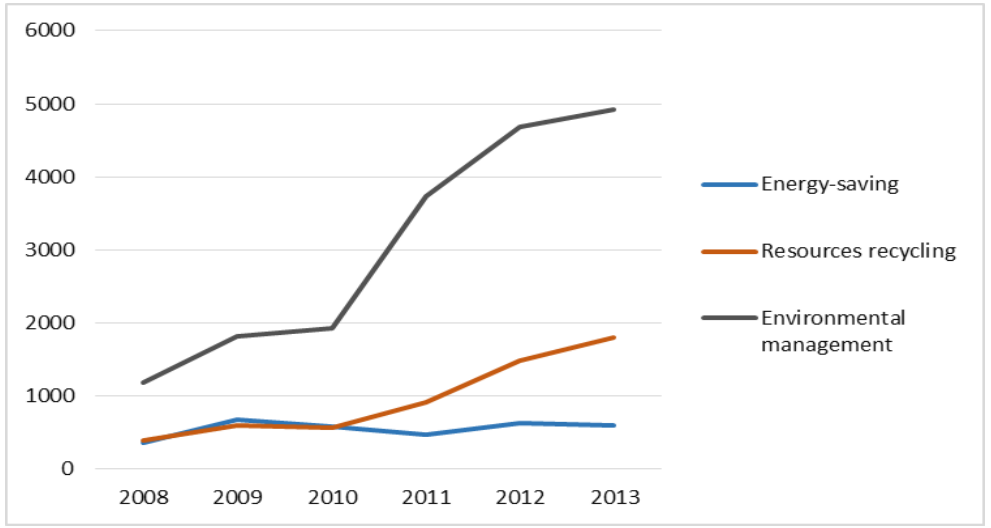

Figure 1. The trends of granted patents in the energy-saving and environmental protection industries

Figure 1 shows the trends of granted patents of the energy-saving and environmental protection industry in 
China from 2008 to 2013. We could find that the characteristics of granted patents in the industry. Firstly, the granted patent numbers of three technical fields have been increasing during the period of 2008-2013, but the growth rates were different. The growth rate of the granted patent number of the environmental management industry is the sharpest, and the growth rate of the granted patent number of the energy-saving industry is the lowest. Secondly, the growth rates of the granted patents are different in different periods in three technical fields. The growth rates were lower in three technical fields during 2008-2010. The growth rate of granted patents of environmental management industry was the highest, but the growth rate of granted patents of the resource recycling industry was low during 2010-2012. The granted patents numbers of the energy-saving industry and the environmental management industry slightly decreased during 2012-2013. Apparently, the innovation capability of the environment management industry was significantly stronger than that of the other two industries in this period.

\subsubsection{The domestic and foreign granted patents distributions of in the tree technical fields}

The domestic and foreign patents distributions of the three technical fields are shown in figure 2 and these patents were granted by State Intellectual Property Office of the PRC (SIPO) from 2008 to 2013. Two characteristics can be found from figure 2: firstly, the domestic granted patents are dominant in the three technical fields of the energy-saving and environmental protection industry in China. There are obvious advantages in the three technical domains for domestic patentees, and foreign patentees are not threats to the related industrial development in China. Secondly, there are different technical advantages degrees in various technologies for the holders of domestic granted patents. The patents advantages of the environmental management industry are the most obvious, slightly followed by the resources recycling industry, and the energy-saving industry is the weakest.

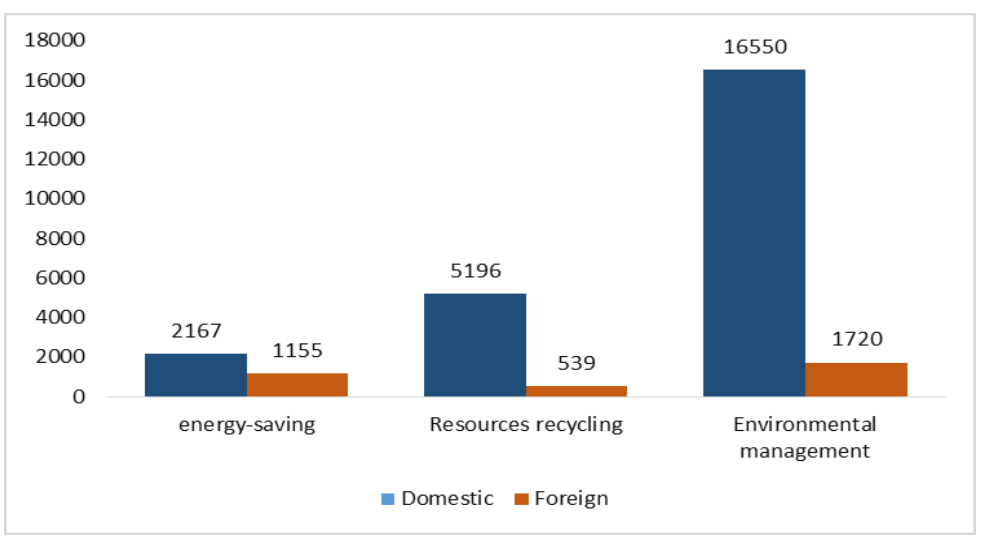

Figure 2. The domestic and foreign granted patents distributions of three fields

\section{THE GRANTED PATENTS DISTRIBUTIONS OF IN THE ENERGY-SAVING INDUSTRY}

The technical field of the energy-saving industry includes the industrial boiler design and manufacturing technology (F22B9/00-F22B9/18, F22B27/00-F22B27/16, and F22B29/00-F22B29/12), the waste heat and energy utilization technology (F27D17/00) and the environmentally air conditioning and heat pump technology (F24F1/00-F24F1/04, F24F3/00-F24F3/16, F24F5/00, F25B30/00-F25B30/06).

\subsection{The granted patents distribution of main technologies in the energy-saving industry}

As shown in Figure 3, inventions in the energy-saving industry mainly concentrated on the environmentally air-conditioning and heat pump technology. There are 2899 granted patents in this technical field, which are accounted for $87.3 \%$ in all granted patents in the industry, and there are 388 granted patents in the technical field 
of the waste heat and energy utilization. The industrial boiler design and manufacturing technology only get 35 granted patents in the past six years, which is the least in the three technical fields in the energy-saving industry.

From Figure 3, we could draw a conclusion: firstly, there is serious imbalance of the granted patents distribution in the energy-saving industry from 2008 to 2013. It primarily focused on the environmentally air-conditioning and heat pump technology, while the innovative capabilities of other two technologies need to enhance; secondly, the competition of the environmentally air-conditioning and heat pump technology will be more acute in the future.

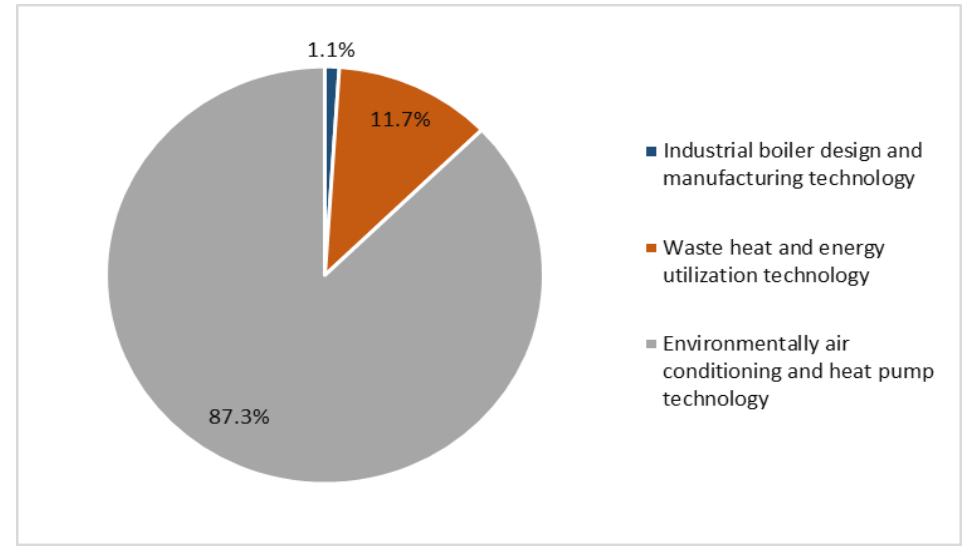

Figure 3. The granted patents distribution of main fields of the energy-saving industry

\subsection{The domestic and foreign granted patents distributions of the energy-saving industry}

The domestic and foreign granted patents distribution of major technical fields in the energy-saving industry (Figure 4) can be found two features. Firstly, there are generally consistent on the domestic and foreign granted patents distributions in the energy-saving industry. The granted patents distributions of both extremely focusing on the environmentally air-conditioning and heat pump technology, and there are relatively small proportions in the waste heat and energy utilization technology and the industrial boiler design and manufacture technology. Secondly, the domestic granted patents amount is absolutely more than that of foreign granted patents in various technical fields. But the gap multiples of domestic and foreign granted patents are not identical. The number of domestic granted patents almost is seven times that of foreign granted patents in the waste heat and energy utilization technology, and is less than doubled in other two technical fields. This shows that the distributions of domestic and foreign granted patents are basically focus on main technical fields in energy-saving industry, however, the domestic granted patents of the waste heat and energy utilization technology has more advantages in China

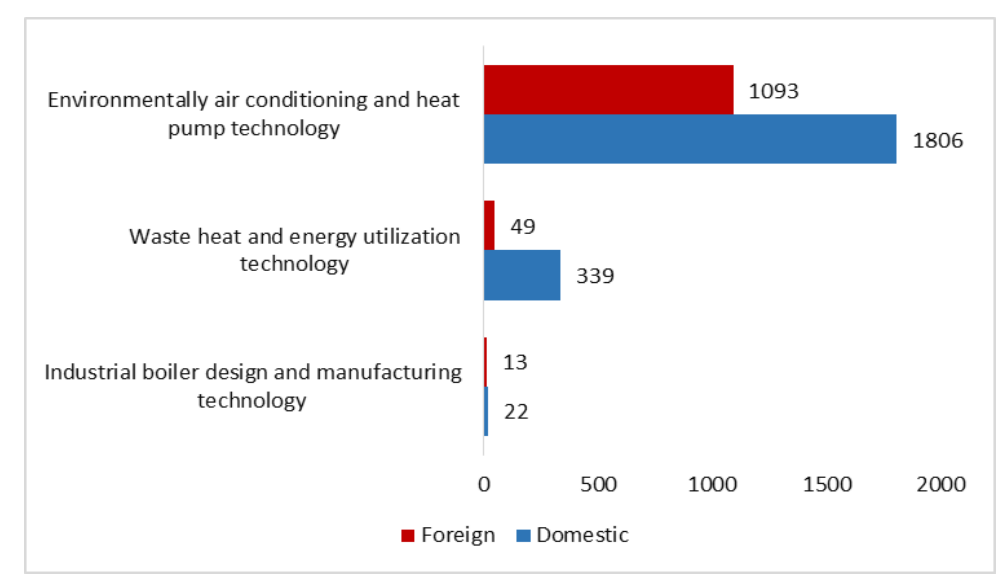

Figure 4. The domestic and foreign granted patents distributions 
of major fields in energy-saving industry

\section{THE GRANTED PATENTS DISTRIBUTIONS OF THE RESOURCES RECYCLING INDUSTRY}

The technologies of the resources recycling industry include the low-grade metal ore recycling technology (B03B7/00, B03B9/06, B03D1/00-B03D1/26), the comprehensive utilization of desulfurization gypsum technology (C04B7/04, C04B11/00-C04B11/30, C04B28/14-C04B28/16), the comprehensive utilization of coal gangue technology(C04B18/04-C04B18/12, C10L5/48), the food waste treatment and comprehensive utilization technology (B09B1/00, B09B3/00, A23K1/10), the waste material dismantling and sorting processing technology (B29B17/00-B29B17/02, H01M6/25, H01M10/54, H01J9/52), the key re-creation technology (C05F9/00-C05F9/04, B22F8/00), the urban sewage sludge recycling technology (C02F11/00-C02F11/02, C05F7/00-C05F7/04).

\subsection{The granted patents distribution of the main fields in the resources recycling industry}

The features of the granted patents distribution of the main technologies in the resources recycling industry in China from 2008 to 2013 (Figure 5) are as follows: Firstly, the granted patents of the resource recycling industry mainly focused on the food waste treatment and comprehensive utilization technology and the urban sewage sludge recycling technology, which are more related to human's daily living. Secondly, they are relatively uniform for the granted patents distributions of the low-grade metal ore recycling technology, the comprehensive utilization of desulfurization gypsum technology, and the comprehensive utilization of coal gangue technology. Thirdly, their granted patents amounts of the waste material dismantling and sorting processing technology and the key re-creation technology are lower, and their roles are weaker in the resource recycling industry.

Therefore, the technological innovational capacity of the food waste treatment and comprehensive utilization technology and the urban sewage sludge recycling technology are obviously leading the industrial development, while the technological innovational capacity of the waste material dismantling and sorting processing technology and the key re-creation are relatively weak in the resources recycling industry in China.

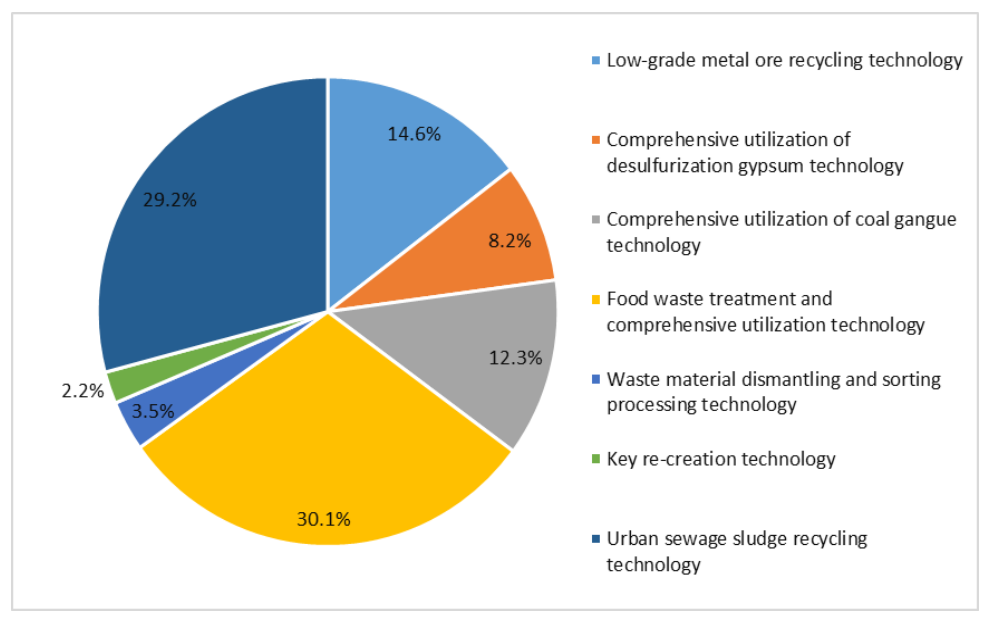

Figure 5. The granted patents distribution of the main fields

of the resources recycling industry

\subsection{The domestic and foreign granted patents distributions of the resources recycling industry}

Figure 6 shows the domestic and foreign granted patents distributions of major technologies in the resources recycling industry in China. Three features could be drawn from it. Firstly, the number of domestic granted patents is more than that of foreign granted patents in the resources recycling industry in China. 
Secondly, the granted patents numbers of the food waste treatment and comprehensive utilization industry and the urban sewage sludge recycling industry are the key technical fields at home and abroad, however the granted patents number of the key re-creation technologies is relatively low, especially the number of foreign patents. Thirdly, the domestic granted patents number is accounted for a larger ratio of the comprehensive utilization of coal gangue technology, while the proportion of the foreign granted patents is very low. This indicates that the domestic innovational capability is stronger in the comprehensive utilization of coal gangue technology, and the foreign innovational capability is stronger in the waste material dismantling and sorting processing technology.

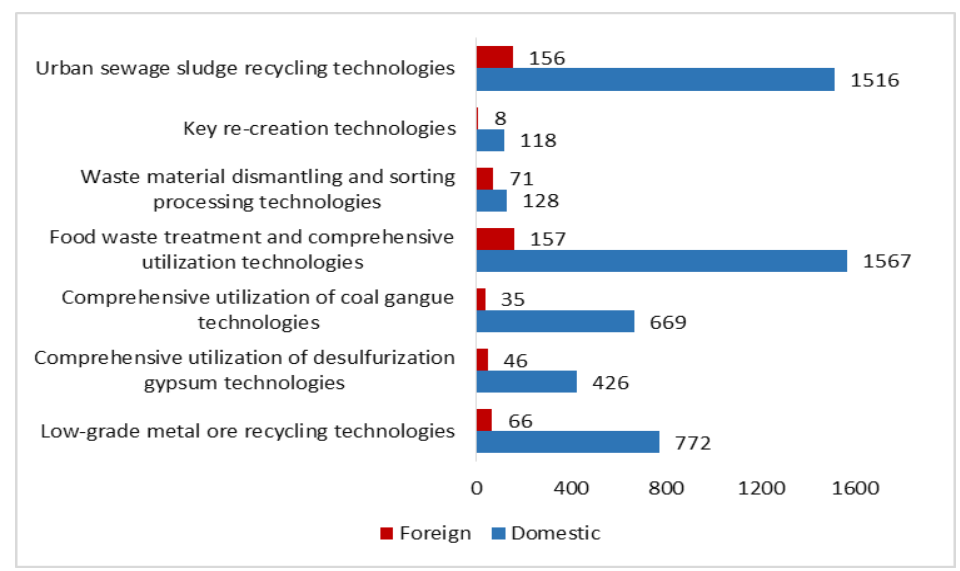

Figure 6. The domestic and foreign granted patents distributions of major fields of the resources recycling industry

We could make a conclusion: the food waste treatment and comprehensive utilization and the urban sewage sludge recycling technologies are the major innovative technical fields at home and abroad in the resources recycling industry; the comprehensive utilization of coal gangue technology place an important role in technical innovations of the resources recycling industry.

\section{THE GRANTED PATENTS DISTRIBUTIONS OF THE ENVIRONMENTAL MANAGEMENT INDUSTRY}

Main technologies of the resource recycling industry include the heavy metal wastewater, waste gas, waste residue pollution control technology (C02F1/62-C02F1/64, B01D53/64), the flue gas desulfurization technology (B01D53/48-B01D53/60), the high concentration organic wastewater control technology (C02F1/00-C02F1/78, C02F3/00-C02F3/34, C02F9/00-C02F9/14), the heavy metals \& POPs (Persistent Organic Pollutants) contaminated soil remediation technology (B09C1/00-B09C1/10).

\subsection{The granted patents distribution of main fields of the environmental management industry}

From the granted patents distribution of main technologies in the environmental management industry (Figure 7), we could find that the granted patents number of the environmental management industry is 18270 from 2008 to 2013, which is completely unbalanced to other technical fields. In other words, more than $80 \%$ of granted patents in the industry focused on the high concentration organic wastewater control technology. The granted patents number of the high concentration organic wastewater control technology is more than others. There are serious problems of industrial organic waste water stimulated technological innovations in this field. The continuous innovation abilities of the heavy metal wastewater, waste gas, waste residue pollution control technology and the heavy metals \& POPs contaminated soil remediation technology are insufficient, accounted for only about $3 \%$ of the granted patents number of the industry. 
Therefore, the innovative capability of the high concentration organic wastewater control technology is the strongest, while the innovative capabilities of the heavy metal wastewater, waste gas, waste residue pollution control technology and the heavy metals \& POPs contaminated soil remediation technology still need to greatly improve.

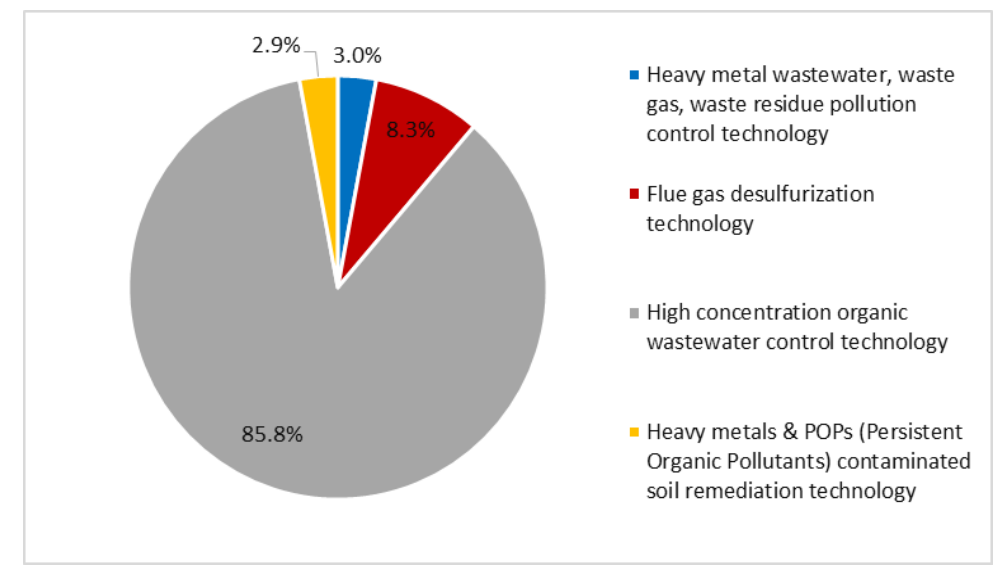

Figure 7. The granted patents distribution of main technologies of the environmental management industry

\subsection{The domestic and foreign granted patents distributions of the environmental management industry}

As shown in the granted patents distributions of the environmental management industry at home and abroad (Figure 8), we could find the following features. Firstly, the domestic granted patents number is far more than the foreign granted patents number of the environmental management industry in China. Secondly, the distributions of domestic and foreign granted patents both significantly concentrate on the high concentration organic wastewater control technical field. It indicates that the technical field of the high concentration organic wastewater control technology is the key domain in the environmental management industry in China.

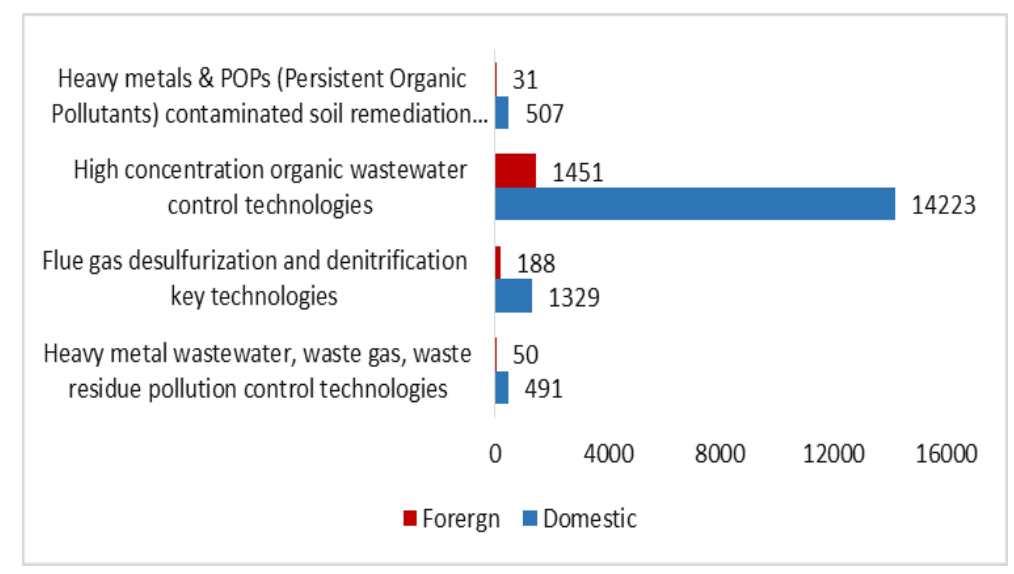

Figure 8. The domestic and foreign granted patents distributions

of the environmental management industry

\section{CONCLUSIONS}

The energy-saving and environmental protection industry is one of the seven strategic emerging industries, which is the key industry to change the economic development mode, promote and upgrade the industrial chain in China. ${ }^{[10]}$ By analyzing the granted patents distribution of the energy-saving and environmental protection industry in China from 2008 to 2013, we could draw the following four conclusions: Firstly, the technological 
development of the energy-saving and environmental protection industry developed rapidly, but the development of sub-technology industries is not balanced, and the innovative capability of the environmental management industry is the strongest. Secondly, technological innovations of the energy-saving industry are focused on the environmentally air-conditioning and heat pump technology, and technological innovations of the resources recycling industry are mainly concentrated on the food waste treatment and comprehensive utilization technology and the urban sewage sludge recycling technology, and technological innovations of the environmental management industry are highly focused on the high concentration organic wastewater control technology. Thirdly, the granted patents distributions of the key strategic technical fields are unbalanced, of which the granted patents of the environmental management industry have the largest share. Fourthly, the domestic granted patents distributions are basically similar to that of foreign granted patents in the energy-saving and environmental protection industry in China, but the numbers of domestic granted patents are more than the numbers of foreign granted patents.

\section{ACKNOWLEDGEMENT}

This research was supported by the National Natural Science Foundation of China (71373221) and the Soft Science Project of State Intellectual Property Office of China (SS13-A-09).

\section{REFERENCES}

[1] The State Council of PRC. (2010). Development plans of " $12^{\text {th }}$ five-year" for the national strategic emerging industries.

[2] Janghyeok Y, Kwangsoo K. (2012). An analysis of property-function based patent networks for strategic R\&D planning in fast-moving industries: The case of silicon-based thin film solar cells [J]. Expert Systems with Applications, 39(9):4409-7717.

[3] Brent B. A, Walter G. P. (2007). The influence of patent protection on firm innovation investment in manufacturing industries [J]. Journal of International Management, 13 (2):91-109.

[4] Liu Fudong, Zhu Xuezhong, Wen Jiachun. (2011). Study on the patent system oriented to low-carbon develops [J]. China Soft Science Magazine, (7): 25-30. (in Chinese)

[5] The State Intellectual Property Office of PRC. (2012). The Management Measures of Priority examination of invention patent applications. (in Chinese)

[6] Bingbin Lu. (2013). Expedited patent examination for green inventions: Developing countries policy choice [J]. Energy Policy, 61(10): 1529-1538.

[7] Yu Jiang, Chen Kaihua. (2012). Current situation and challenge of technological innovations in Chinese strategic emerging industries: a patent-bibilometric perspective [J]. Studies in Science of Science, 30 (5): 682-695. (in Chinese)

[8] Zhou Ying, Qiu Honghua. (2010). A comparative study on green technology patents of American and Japanese automakers as well as its enlightenment [J]. Journal of Intelligence, 29 (2): 21-26. (in Chinese)

[9] Kaihua Chen, Jianchen Guan. (2011). A bibliometric investigation of research performance in emerging nanobio pharmaceuticals [J]. Journal of Informatics, 5 (2): 233-247.

[10] Zhang Yangping, Tang Xuan. (2012). Development theories of strategic emerging industries and practice experiences for reference: A case study of the energy saving and environmental protection industry in Guangdong province [J]. Modern Urban Research, 27(7): 81-87. (in Chinese) 